\title{
The In Vitro Susceptibility of Biofilm Forming Medical Device Related Pathogens to Conventional Antibiotics
}

\author{
Garry Laverty, Mahmoud Y. Alkawareek, and Brendan F. Gilmore \\ Biomaterials, Biofilm and Infection Control Research Group, School of Pharmacy, Queens University of Belfast, Medical Biology Centre, \\ 97 Lisburn Road, Belfast BT9 7BL, UK \\ Correspondence should be addressed to Brendan F. Gilmore; b.gilmore@qub.ac.uk
}

Received 31 October 2013; Accepted 10 February 2014; Published 1 June 2014

Academic Editors: T. Coenye and L. M. Teixeira

Copyright (C) 2014 Garry Laverty et al. This is an open access article distributed under the Creative Commons Attribution License, which permits unrestricted use, distribution, and reproduction in any medium, provided the original work is properly cited.

Minimum inhibitory concentration (MIC), minimum bactericidal concentration (MBC), and minimum biofilm eradication concentration (MBEC) and kill kinetics were established for vancomycin, rifampicin, trimethoprim, gentamicin, and ciprofloxacin against the biofilm forming bacteria Staphylococcus epidermidis (ATCC 35984), Staphylococcus aureus (ATCC 29213), Methicillin Resistant Staphylococcus aureus (MRSA) (ATCC 43300), Pseudomonas aeruginosa (PAO1), and Escherichia coli (NCTC 8196). MICs and MBCs were determined via broth microdilution in 96-well plates. MBECs were studied using the Calgary Biofilm Device. Values obtained were used to investigate the kill kinetics of conventional antimicrobials against a range of planktonic and biofilm microorganisms over a period of 24 hours. Planktonic kill kinetics were determined at 4xMIC and biofilm kill kinetics at relative MBECs. Susceptibility of microorganisms varied depending on antibiotic selected and phenotypic form of bacteria. Gram-positive planktonic isolates were extremely susceptible to vancomycin (highest MBC: $7.81 \mathrm{mg} \mathrm{L}^{-1}$ : methicillin sensitive and resistant S. aureus) but no MBEC value was obtained against all biofilm pathogens tested (up to $1000 \mathrm{mg} \mathrm{L}^{-1}$ ). Both gentamicin and ciprofloxacin displayed the broadest spectrum of activity with MIC and MBCs in the $\mathrm{mg} \mathrm{L}^{-1}$ range against all planktonic isolates tested and MBEC values obtained against all but S. epidermidis (ATCC 35984) and MRSA (ATCC 43300).

\section{Introduction}

Medical device related infections present an increasing burden on health care systems with concomitant high rates of patient morbidity and mortality [1]. Their increased clinical presentation and associated problems are due mainly to the ability of microorganisms to form resistant biofilms at the biomaterial surface. Biofilms are heterogeneous by nature and contain a subpopulation of dormant persister cells that show tolerance to treatment by standard antimicrobial regimens [2]. In the presence of many standard antibiotics these persister cells reduce metabolic processes and uptake of nutrients and cease multiplying, only to become active again when the antibiotic is at subtherapeutic levels [3]. In order to be clinically successful in the treatment of a medical device infection, the antibiotic's pharmacokinetic properties, rate of kill, and concentration must be assessed against a spectrum of relevant biofilm forming microorganisms. This study is set out to obtain an indication of the ability of currently prescribed antimicrobials to eradicate both planktonic and biofilm forms of these device related pathogens in vitro, with conclusions made to their relative success.

On presentation of a medical device related infection there are several treatment options available. Selection of treatment is dependent on a multitude of factors including the location of device and how easily it is available to treatment or for removal, the likely or proven causative microorganism(s), the clinical profile/health of the patient and the presence of comorbidities, and the risk factors for infection. Treatment strategies can not only vary between different countries and continents but also differ depending on local antimicrobial susceptibility data and on antimicrobial formularies/policies of individual hospitals or health trusts [4].

Updated guidelines published by Mermel et al. provides accurate guidelines for clinical practice in coordination with the Infectious Disease Society of America for the diagnosis and treatment of intravascular catheter-related infections [5]. The two major treatment options involve either removal of 
the device, for example, a short term peripheral catheter that is easily removed, or if possible salvaging the device via use of antimicrobial chemotherapy. Therapy may be initiated parenterally or through use of the antibiotic lock technique. The antibiotic lock technique involves filling the catheter lumen with a high concentration of antimicrobials, commonly glycopeptides, ciprofloxacin, and aminoglycosides, for 7-14 days [6]. Such therapy may be used concurrently with parenteral or oral antimicrobials, anticoagulants, and thrombolytics [7-9]. In symptomatic medical device infection, at risk patients may be initiated on empirical therapy before the causative pathogen(s) is identified. Empirical therapy can vary in both length and dosage form but normally consists of high dose parenteral drugs for 7-10 days with drug of choice based on suspected pathogen $[10,11]$. Where Gram-positive infections are suspected empirical therapy should involve an aminoglycoside, for example, gentamicin, or rifampicin together with the glycopeptide vancomycin [12]. Such a treatment plan takes into account the potential for methicillin resistant strains to be prevalent. Where methicillin resistance can be confidently dismissed the penicillinaseresistant penicillin's, nafcillin or oxacillin, may be used. In cases where $P$. aeruginosa or Gram-negative bacilli are suspected a cephalosporin (third or fourth generation) may be utilised including cefepime or ceftazidime and aztreonam [5]. The potential for antimicrobial resistance to be present and develop should always be considered upon initiation of therapy. Organisms should be cultured and susceptibility tests should be performed to allow treatment to be tapered for individual infections, thereby allowing a more efficient narrow spectrum antimicrobial to be adopted and the potential for resistance to be lowered.

When coagulase negative staphylococci infection is implicated vancomycin and other glycopeptides are the treatment of choice often in combination with teicoplanin due to the high level of resistance to $\beta$-lactam antibiotics [13]. Removal of the device may be considered in at risk patients with 5-7 days of antimicrobial chemotherapy. In patients where the aim is to salvage the device therapy should continue for a period of 10-14 days $[14,15]$. S. aureus catheterrelated bloodstream infection required the use of intravenous $\beta$-lactam antibiotics, for example, flucloxacillin and oxacillin, with first generation cephalosporins like cefazolin used on presentation of penicillin allergic patients if the isolated microorganism is deemed susceptible [16]. Methicillin resistant $S$. aureus requires the use of vancomycin alone first or in combination with rifampicin, fosfomycin, fusidic acid, cotrimoxazole, clindamycin, or the newer fluoroquinolones if complications develop [17].

Gram-positive rods including Corynebacterium, Bacillus, and rapidly producing Mycobacterium species are particularly problematic in medical device related infection. Their presence normally will require catheter withdrawal and treatment with intravenous vancomycin [18-20]. For mycobacteria a range of antibacterials may be required including aminoglycosides, imipenem/cilastatin, cotrimoxazole, macrolides, cefoxitin, and tetracyclines [21]. Where Gram-negative rod infection is implicated catheter withdrawal may be required if at risk patients are infected with species other than P. aeruginosa, Acinetobacter baumannii, Burkholderia cepacia complex, and Stenotrophomonas maltophilia [22]. The most effective antibiotics against E. coli are imipenem and ciprofloxacin. E. coli may also require the use of a cephalosporin with the second generation cephalosporin, cephamycin, more active than other cephalosporins in treatment of biofilm forming E. coli [23]. P. aeruginosa infections may involve the use of a third or fourth generation cephalosporin or carbapenem or an antipseudomonal $\beta$ lactam like ticarcillin, piperacillin, and mexlocillin in combination with an aminoglycoside [16]. Levofloxacin may also have a role in treatment schedules [24].

Where circumstances allow intravenous treatment may be switched to an oral antibiotic. Antibiotics that have been shown to have high oral bioavailability and tissue penetration include rifampicin, linezolid, quinolones, for example, ciprofloxacin, and a combination of trimethoprim and sulfamethoxazole (cotrimoxazole) [25]. Choice of antibiotic treatment is dependent on the nature and severity of infection. If long term antibiotic intervention fails, as is often the case, surgery is a requirement for the removal of the device. As with the majority of medical disease states prevention of medical device related infection is always considered preferable to allow infection to become established.

The aim of this study was to compare the in vitro efficacy of a range of selected antibiotics: vancomycin, rifampicin, trimethoprim, gentamicin, and ciprofloxacin, against planktonic and established biofilm forms of medical device related pathogens (S. epidermidis, S. aureus, MRSA, P. aeruginosa, and $E$. coli). Efficacy was measured by obtaining values for $\mathrm{MIC}, \mathrm{MBC}$, and MBEC and determining planktonic and biofilm kill kinetics.

\section{Methodology}

Reduced glutathione, vancomycin (as hydrochloride hydrate), rifampicin, trimethoprim, gentamicin (as disulphate salt), and ciprofloxacin were obtained from Sigma-Aldrich (Dorset, UK). L-histidine and L-cysteine were obtained from Novabiochem, Merck Chemicals Ltd. (Nottingham, UK). Müeller-Hinton broth and Müeller-Hinton agar were obtained from Oxoid (Basingstoke, UK) and sterilised via autoclaving, with its sterilised form used throughout the study. The microorganisms selected for analysis were the best biofilm forming isolates of each species analysed based on quantification of biofilm formation results using a crystal violet staining method employed by Stepanović et al. [26] and quantifying the growth of different biofilm grown on the Calgary Biofilm Device. These were S. epidermidis (ATCC 35984), S. aureus (ATCC 29213), MRSA (ATCC 43300), P. aeruginosa (PAO1), and E. coli (NCTC 8196). All isolates of microorganisms are stored at $-80^{\circ} \mathrm{C}$ on Microbank Preserver beads (Pro-Lab Diagnostics, Cheshire, UK).

Broth microdilution tests were performed in 96-well microtitre plates to determine MIC and MBC as described previously by our group [27]. An original working solution of each standard antimicrobial was prepared and $0.22 \mu \mathrm{m}$ sterile was filtered. Antimicrobials tested were vancomycin, rifampicin, trimethoprim, gentamicin, and ciprofloxacin over 
a double dilution range of $1000-0.24 \mathrm{mg} \mathrm{L}^{-1}$. All controls and test concentrations were prepared as eight replicates. Biofilm susceptibility assays were performed using the Calgary Biofilm Device (MBEC Assay for Physiology \& Genetics, Innovotech, Edmonton, Alberta, Canada), a rapid, high throughput assay for the determination of microbial biofilm susceptibility to antimicrobial challenge. The biofilm assay was conducted essentially according to the manufacturer's instructions, as demonstrated by Ceri et al. [28], with some slight modifications. The inocula were diluted further in Müeller-Hinton broth in order to achieve a biofilm viable count of $2 \times 10^{5} \mathrm{CFU} /$ peg after 24 hours. The plates were then incubated for 24 hours at $37^{\circ} \mathrm{C}$ and $95 \%$ relative humidity in a gyrorotary incubator. The original MBEC lid containing adhere biofilm was placed into the wells of the challenge plate (containing antimicrobials: $1000-1.95 \mathrm{mg} \mathrm{L}^{-1}$ ) and then incubated for 24 hours at $37^{\circ} \mathrm{C}$ and $95 \%$ relative humidity in a gyrorotary incubator. The recovery plate wells corresponding to the lowest concentration at which no observable growth was apparent after 24 hours were also designated to be the MBEC value. For verification purposes, optical density in each well was recorded at $550 \mathrm{~nm}\left(A_{550}\right)$ using a Tecan Sunrise plate reader and compared with negative (no-growth) control. Results obtained for MIC, MBC, and MBEC are displayed in Dataset Item 1 (Table).

For planktonic kill kinetics microorganisms under investigation were grown over $18-24$ hours at $37^{\circ} \mathrm{C}$ in MüellerHinton broth and this suspension was further diluted in static liquid cultures of Quarter Strength Ringers Solution (QSRS) to approximately $2 \times 10^{5} \mathrm{CFU} \mathrm{mL}^{-1}$ stock solution, as verified by a Miles and Misra total viable count. Antimicrobial was tested at concentrations of four times the MIC where MIC was shown to be $<1000 \mathrm{mg} \mathrm{L}^{-1}$. The selection of an antimicrobial concentration of four times the MIC allowed for effective analysis of the kill kinetics of each antimicrobial as utilised by Stratton et al. [29, 30]. Five replicates of each antimicrobial/static inoculum solution were formulated. Time points selected to assess planktonic kill kinetics were 10 minutes (0.1667 hours), 1, 1.5, 2, 4, 6, and 24 hours. At each of these time points the antimicrobial/static inoculum solution was vortexed and serially diluted using a solution of universal neutraliser. A stock solution of universal neutraliser was formed by addition of $1.0 \mathrm{~g}$ of L-histidine, $1.0 \mathrm{~g}$ of Lcysteine, and $2.0 \mathrm{~g}$ of reduced glutathione to a sterile $20 \mathrm{~mL}$ volumetric flask and this was made up accurately to $20 \mathrm{~mL}$ using sterile water. To ensure sterility this solution was passed through a syringe with a $0.22 \mu \mathrm{m}$ sterile filter twice. This stock solution was stored as aliquots in sterile eppendorfs and frozen at $-20^{\circ} \mathrm{C}$ until required. $500 \mu \mathrm{L}$ of the universal neutralizer was added to $20 \mathrm{~mL}$ of $0.9 \% \mathrm{NaCl}$ solution for use in universal inhibitor-rinse plates. Aliquots of each dilution were added to Müeller-Hinton agar plates and incubated for 24 hours at $37^{\circ} \mathrm{C}$ in a stationary incubator and scored for growth the following day. Drug carryover was also addressed according to Pankuch et al. [31]. The ability of the standard antimicrobials to eradicate 24-hour biofilms was evaluated using MBEC plates similarly to the method used by Smith et al. [32]. After incubation mature 24-hour biofilm of each susceptible microorganism was challenged with the MBEC value of each antimicrobial if the MBEC value was equal to or lower than $1000 \mathrm{mg} \mathrm{L}^{-1}$. No activity corresponds to MBEC value greater than $1000 \mathrm{mg} \mathrm{L}^{-1}$, outside the tested concentration range, and therefore those antimicrobials were not tested. A concentration of antimicrobial corresponding to the MBEC value in QSRS was formulated and added to a standard 96-well plate with a $200 \mu \mathrm{L}$ volume of antimicrobial in each well from columns 1 to 5 to form a challenge plate. Columns 6 to 12 of the challenge plate corresponded to positive (columns 6-11) and negative controls (column 12) and contained a $200 \mu \mathrm{L}$ volume of QSRS. The MBEC lid was placed into the corresponding wells of the challenge plate and incubated at $37^{\circ} \mathrm{C}$ and $95 \%$ relative humidity in a gyrorotary incubator until each corresponding time point is reached. A dilution plate was set up to include both $0.9 \%$ $\mathrm{NaCl}$ solution and universal neutraliser solutions which are present in separate wells. The first two rows (A and B) of a standard 96 -well plate contained $200 \mu \mathrm{L}$ of $0.9 \% \mathrm{NaCl}$ solution whereas row C contained $200 \mu \mathrm{L}$ of universal neutraliser solution. The remaining 5 rows $(\mathrm{D}-\mathrm{H})$ corresponded to serial dilution columns and contained $180 \mu \mathrm{L}$ of $0.9 \% \mathrm{NaCl}$ solution in each well. At the time points $0.16667,1,1.5,2,4$, 6 , and 24 hours 5 pegs were removed, using sterile flamed pliers, from the MBEC lid corresponding to antimicrobially challenged biofilm and further 5 pegs removed from the area corresponding to positive controls for the biofilm and placed into the first row of separate wells in corresponding dilution plates. The first row of wells contained $0.9 \% \mathrm{NaCl}$ solution (row A) and corresponded to rinse wells with the removed pegs being rinsed for 2 minutes before they were moved to row B for a further 2 minutes rinse via sterile forceps. After the second rinse the pegs were placed in wells in row $\mathrm{C}$ of the dilution plate that contained universal neutraliser solution and were sonicated at the highest setting for 10 minutes to remove adhered microorganism. After sonication the peg was removed from row $\mathrm{C}$ and placed in row $\mathrm{B}$, using sterile forceps, to ensure that removed microorganisms did not read here. A serial dilution was then performed from row $\mathrm{C}$ to row $\mathrm{H}$ via Miles et al. methods [33] with $20 \mu \mathrm{L}$ aliquots of each dilution added to Müeller-Hinton agar plates and incubated for 24 hours at $37^{\circ} \mathrm{C}$ in a stationary incubator and scored for growth the following day. Results for planktonic and biofilm rate of kill are displayed in Dataset Items 2-18 (Tables) and represented in Figures 1, 2, 3, 4, 5, 6, 7, 8, and 9.

\section{Dataset Description}

The dataset associated with this Dataset Paper consists of 18 items which are described as follows.

Dataset Item 1 (Table). MIC, MBC, and MBEC (all mg L ${ }^{-1}$ ) of vancomycin, rifampicin, trimethoprim, gentamicin, and ciprofloxacin against S. epidermidis (ATCC 35984), S. aureus (ATCC 29213), MRSA (ATCC 43300), P. aeruginosa (PAO1), and E. coli (NCTC 8196) based on eight replicates.

Column 1: Antimicrobial

Column 2: MIC against S. epidermidis $\left(\mathrm{mg} \mathrm{L}^{-1}\right)$ 


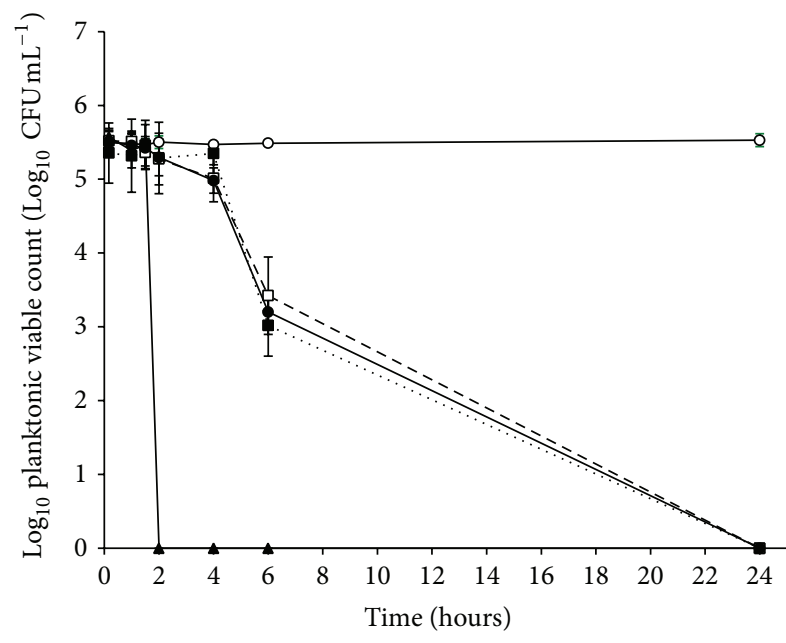

FIGURE 1: $\log _{10}$ graph showing kill kinetics and $\log _{10}$ planktonic viable counts ( $\log _{10} \mathrm{CFU} \mathrm{mL}{ }^{-1}$ ) of S. epidermidis (ATCC 35984) (positive control: open circles, full line) over a period of 24 hours of exposure to four times MIC value $\left(\mathrm{mg} \mathrm{L}^{-1}\right)$ of active standard antimicrobials (vancomycin $10 \mathrm{mg} \mathrm{L}^{-1}$ : filled square, dotted line; rifampicin $10 \mathrm{mg} \mathrm{L}^{-1}$ : filled triangle, full line; gentamicin $125 \mathrm{mg} \mathrm{L}^{-1}$ : open square, dotted line; ciprofloxacin $4 \mathrm{mg} \mathrm{L}^{-1}$ : full circle, full line) based on five replicates.

\section{Column 3: $\quad \mathrm{MBC}$ against S. epidermidis $\left(\mathrm{mg} \mathrm{L}^{-1}\right)$ \\ Column 4: MBEC against S. epidermidis $\left(\mathrm{mg} \mathrm{L}^{-1}\right)$ \\ Column 5: MIC against S. aureus $\left(\mathrm{mg} \mathrm{L}^{-1}\right)$ \\ Column 6: $\mathrm{MBC}$ against $S$. aureus $\left(\mathrm{mg} \mathrm{L}^{-1}\right)$ \\ Column 7: $\mathrm{MBEC}$ against $S$. aureus $\left(\mathrm{mg} \mathrm{L}^{-1}\right)$ \\ Column 8: MIC against MRSA $\left(\mathrm{mg} \mathrm{L}^{-1}\right)$ \\ Column 9: $\mathrm{MBC}$ against MRSA $\left(\mathrm{mg} \mathrm{L}^{-1}\right)$ \\ Column 10: MBEC against MRSA ( $\left.\mathrm{mg} \mathrm{L}^{-1}\right)$ \\ Column 11: MIC against $P$. aeruginosa $\left(\mathrm{mg} \mathrm{L}^{-1}\right)$ \\ Column 12: $\mathrm{MBC}$ against $P$. aeruginosa $\left(\mathrm{mg} \mathrm{L}^{-1}\right)$ \\ Column 13: MBEC against $P$. aeruginosa $\left(\mathrm{mg} \mathrm{L}^{-1}\right)$ \\ Column 14: MIC against E. coli $\left(\mathrm{mg} \mathrm{L}^{-1}\right)$ \\ Column 15: $\mathrm{MBC}$ against E. coli $\left(\mathrm{mg} \mathrm{L}^{-1}\right)$ \\ Column 16: MBEC against E. coli $\left(\mathrm{mg} \mathrm{L}^{-1}\right)$}

Dataset Item 2 (Table). Rate of kill data (mean) and logged mean $\left(\log _{10}\right)$ for planktonic S. epidermidis (ATCC 35984). In the table, the column Antimicrobial presents the named/relevant antimicrobial and concentration $\left(\mathrm{mg} \mathrm{L}^{-1}\right)$ where colony count was performed; Time, the exposure time (hours); $\log _{10}$ Planktonic Count, the logged mean $\left(\log _{10}\right)$ planktonic count $\left(\log _{10} \mathrm{CFU} \mathrm{mL} \mathrm{m}^{-1}\right)$ of five replicates at each antimicrobial concentration and time; and Standard Deviation, the standard deviation of five replicates at each antimicrobial concentration and time.

Column 1: Antimicrobial

Column 2: Time (h)

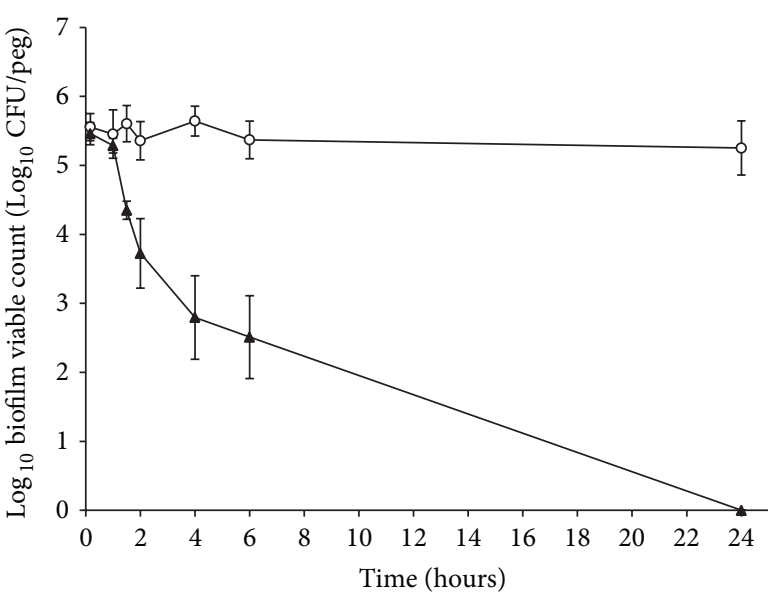

FIGURE 2: $\log _{10}$ graph showing biofilm eradication kinetics and $\log _{10}$ biofilm viable counts ( $\log _{10} \mathrm{CFU} / \mathrm{peg}$ ) of $S$. epidermidis (ATCC 35984) (positive control: open circles, full line) over a period of 24 hours of exposure to MBEC value $\left(\mathrm{mg} \mathrm{L}^{-1}\right)$ of active standard antimicrobials (rifampicin $62.5 \mathrm{mg} \mathrm{L}^{-1}$ : filled triangle, full line) based on five replicates. Vancomycin, trimethoprim, gentamicin, and ciprofloxacin had MBEC values greater than $1000 \mathrm{mg} \mathrm{L}^{-1}$ against S. epidermidis (ATCC 35984) and therefore were not tested for biofilm eradication kinetics.

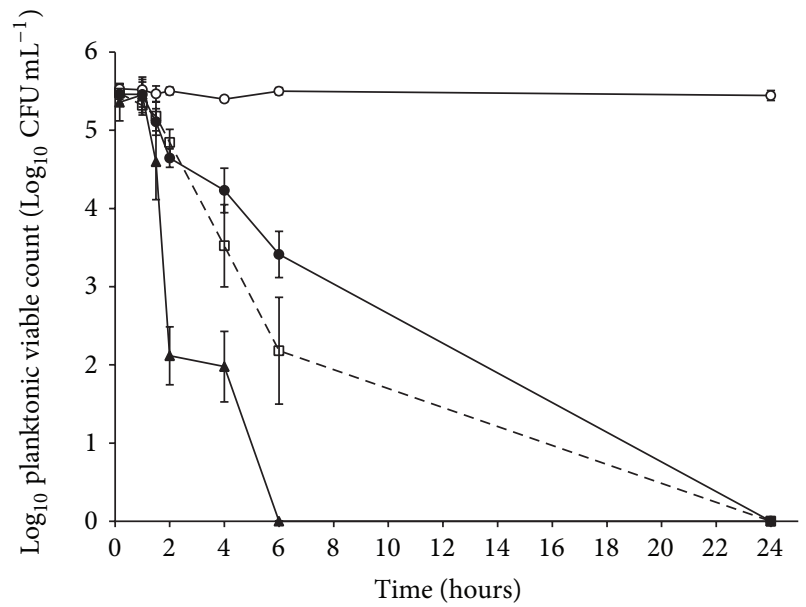

FIgURE 3: $\log _{10}$ graph showing kill kinetics and $\log _{10}$ planktonic viable counts $\left(\log _{10} \mathrm{CFU} \mathrm{mL}{ }^{-1}\right.$ ) of $S$. aureus (ATCC 29213) (positive control: open circles, full line) over a period of 24 hours of exposure to four times MIC value $\left(\mathrm{mg} \mathrm{L}^{-1}\right)$ of active standard antimicrobials (vancomycin $10 \mathrm{mg} \mathrm{L}^{-1}$ : filled square, dotted line; rifampicin $1 \mathrm{mg} \mathrm{L}^{-1}$ : filled triangle, full line; gentamicin $2 \mathrm{mg} \mathrm{L}^{-1}$ : open square, dotted line; trimethoprim $10 \mathrm{mg} \mathrm{L}^{-1}$ : open triangle, dotted line; ciprofloxacin $10 \mathrm{mg} \mathrm{L}^{-1}$ : full circle, full line) based on five replicates.

\section{Column 3: $\log _{10}$ Planktonic Count $\left(\log _{10} \mathrm{CFU} \mathrm{mL} \mathrm{L}^{-1}\right)$}

Column 4: Standard Deviation

Dataset Item 3 (Table). Logged mean $\left(\log _{10}\right)$ planktonic count $\left(\log _{10} \mathrm{CFU} \mathrm{mL} \mathrm{m}^{-1}\right)$ of five positive control replicates for 


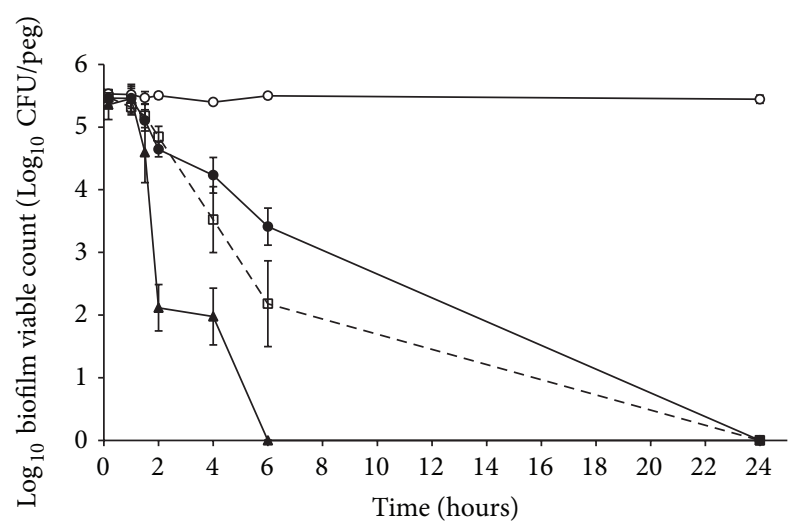

FIGURE 4: $\log _{10}$ graph showing biofilm eradication kinetics and $\log _{10}$ biofilm viable counts ( $\log _{10} \mathrm{CFU} / \mathrm{peg}$ ) of $S$. aureus (ATCC 29213) (positive control: filled diamonds, full line) over a period of 24 hours of exposure to MBEC value $\left(\mathrm{mg} \mathrm{L}^{-1}\right)$ of active standard antimicrobials (rifampicin $15.63 \mathrm{mg} \mathrm{L}^{-1}$ : filled triangle, full line; gentamicin $15.63 \mathrm{mg} \mathrm{L}^{-1}$ : cross, dotted line; ciprofloxacin $500 \mathrm{mg} \mathrm{L}^{-1}$ : full circle, full line) based on five replicates. Trimethoprim and vancomycin had MBEC values greater than $1000 \mathrm{mg} \mathrm{L}^{-1}$ against S. aureus (ATCC 29213) and therefore were not tested for biofilm eradication kinetics.

planktonic S. epidermidis (ATCC 35984) at each time point tabulated at the same time as each tested antimicrobial.

Column 1: Time (h)

Column 2: Vancomycin $\left(\log _{10} \mathrm{CFU} \mathrm{mL} \mathrm{L}^{-1}\right)$

Column 3: Rifampicin $\left(\log _{10} \mathrm{CFU} \mathrm{mL} \mathrm{L}^{-1}\right)$

Column 4: Gentamicin $\left(\log _{10} \mathrm{CFU} \mathrm{mL} \mathrm{m}^{-1}\right)$

Column 5: Ciprofloxacin $\left(\log _{10} \mathrm{CFU} \mathrm{mL} L^{-1}\right)$

Column 6: $\log _{10}$ Planktonic Count

$$
\left(\log _{10} \mathrm{CFU} \mathrm{mL} \mathrm{mL}^{-1}\right)
$$

Column 7: Standard Deviation

Dataset Item 4 (Table). Rate of kill data (mean) and logged mean $\left(\log _{10}\right)$ for biofilm S. epidermidis (ATCC 35984). Vancomycin, trimethoprim, gentamicin, and ciprofloxacin had MBEC values greater than $1000 \mathrm{mg} \mathrm{L}^{-1}$ against S. epidermidis (ATCC 35984) and therefore were not tested for biofilm eradication kinetics. In the table, the column Antimicrobial and Positive Control presents the named/relevant antimicrobial and concentration $\left(\mathrm{mg} \mathrm{L}^{-1}\right)$ where colony count was performed followed by the positive control; Time, the exposure time (hours); $\log _{10}$ Biofilm Count, the logged mean $\left(\log _{10}\right)$ biofilm count $\left(\log _{10} \mathrm{CFU} / \mathrm{peg}\right)$ of five replicates at each antimicrobial concentration and time; and Standard Deviation, the standard deviation of five replicates at each antimicrobial concentration and time.

Column 1: Antimicrobial and Positive Control

Column 2: Time (h)

Column 3: $\log _{10}$ Biofilm Count $\left(\log _{10} \mathrm{CFU}\right)$

Column 4: Standard Deviation

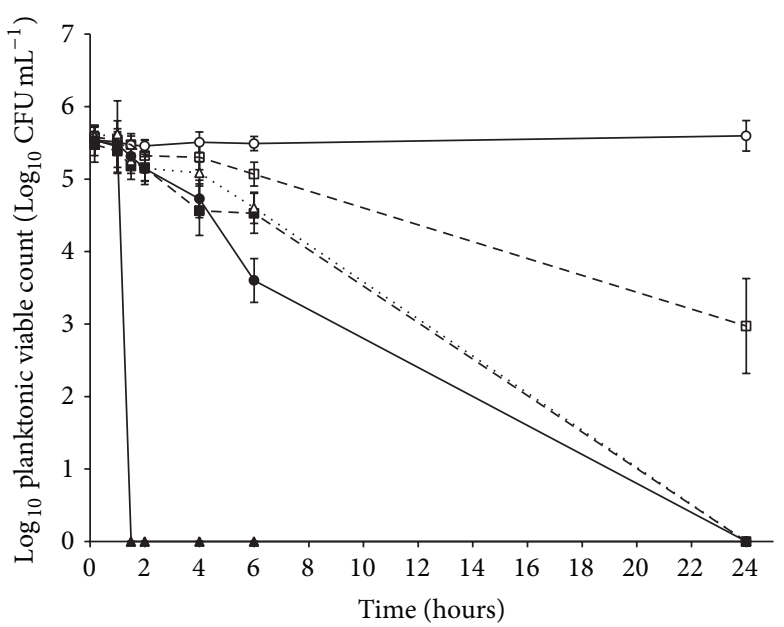

FIGURE 5: $\log _{10}$ graph showing kill kinetics and $\log _{10}$ planktonic viable counts $\left(\log _{10} \mathrm{CFU} \mathrm{mL} \mathrm{m}^{-1}\right.$ ) of MRSA (ATCC 43300) (positive control: filled circles, full line) over a period of 24 hours of exposure to four times MIC value $\left(\mathrm{mg} \mathrm{L}^{-1}\right)$ of active standard antimicrobials (vancomycin $10 \mathrm{mg} \mathrm{L}^{-1}$ : filled square, dotted line; rifampicin $10 \mathrm{mg} \mathrm{L}^{-1}$ : filled triangle, full line; gentamicin $2 \mathrm{mg} \mathrm{L}^{-1}$ : open square, dotted line; trimethoprim $250 \mathrm{mg} \mathrm{L}^{-1}$ : open triangle, dotted line; ciprofloxacin $31.25 \mathrm{mg} \mathrm{L}^{-1}$ : full circle, full line) based on five replicates. No standard antimicrobial was active against the biofilm form of MRSA (ATCC 43300) at concentrations ( $\left.\leq 1000 \mathrm{mg} \mathrm{L}^{-1}\right)$ tested and thus kinetic analysis was not performed.

Dataset Item 5 (Table). Rate of kill data (mean) and logged mean $\left(\log _{10}\right)$ for planktonic S. aureus (ATCC 29213). In the table, the column Antimicrobial presents the named/relevant antimicrobial and concentration $\left(\mathrm{mg} \mathrm{L}^{-1}\right)$ where colony count was performed; Time, the exposure time (hours); $\log _{10}$ Planktonic Count, the logged mean $\left(\log _{10}\right)$ planktonic count $\left(\log _{10} \mathrm{CFU} \mathrm{mL} \mathrm{L}^{-1}\right)$ of five replicates at each antimicrobial concentration and time; and Standard Deviation, the standard deviation of five replicates at each antimicrobial concentration and time.

Column 1: Antimicrobial

Column 2: Time (h)

Column 3: $\log _{10}$ Planktonic Count

$$
\left(\log _{10} \mathrm{CFU} \mathrm{mL} L^{-1}\right)
$$

Column 4: Standard Deviation

Dataset Item 6 (Table). Logged mean $\left(\log _{10}\right)$ planktonic count $\left(\log _{10} \mathrm{CFU} \mathrm{mL} \mathrm{L}^{-1}\right)$ of five positive control replicates for planktonic S. aureus (ATCC 29213) at each time point tabulated at the same time as each tested antimicrobial.

Column 1: Time (h)

Column 2: Vancomycin $\left(\log _{10} \mathrm{CFU} \mathrm{mL} \mathrm{m}^{-1}\right)$

Column 3: Rifampicin $\left(\log _{10} \mathrm{CFU} \mathrm{mL} L^{-1}\right)$

Column 4: Gentamicin $\left(\log _{10} \mathrm{CFU} \mathrm{mL} \mathrm{L}^{-1}\right)$

Column 5: Ciprofloxacin $\left(\log _{10} \mathrm{CFU} \mathrm{mL} L^{-1}\right)$ 


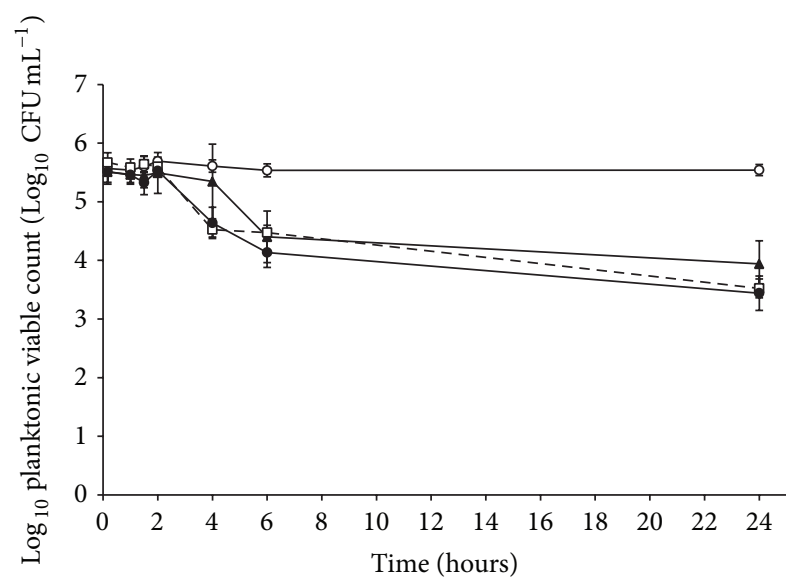

FIGURE 6: $\log _{10}$ graph showing kill kinetics and $\log _{10}$ planktonic viable counts $\left(\log _{10} \mathrm{CFU} \mathrm{mL} \mathrm{L}^{-1}\right.$ ) of $P$. aeruginosa (PAO1) (positive control: filled circles, full line) over a period of 24 hours of exposure to four times MIC value $\left(\mathrm{mg} \mathrm{L}^{-1}\right)$ of active standard antimicrobials (rifampicin $125 \mathrm{mg} \mathrm{L}^{-1}$ : filled triangle, full line; gentamicin $4 \mathrm{mg} \mathrm{L}^{-1}$ : cross, dotted line; ciprofloxacin $1 \mathrm{mg} \mathrm{L}^{-1}$ : full circle, full line) based on five replicates.

\section{Column 6: $\log _{10}$ Planktonic Count $\left(\log _{10} \mathrm{CFU} \mathrm{mL} L^{-1}\right)$}

\section{Column 7: Standard Deviation}

Dataset Item 7 (Table). Rate of kill data (mean) and logged mean $\left(\log _{10}\right)$ for biofilm $S$. aureus (ATCC 29213). Trimethoprim and vancomycin had MBEC values greater than $1000 \mathrm{mg} \mathrm{L}^{-1}$ against S. aureus (ATCC 29213) and therefore were not tested for biofilm eradication kinetics. In the table, the column Antimicrobial presents the named/relevant antimicrobial and concentration $\left(\mathrm{mgL}^{-1}\right)$ where colony count was performed; Time, the exposure time (hours); $\log _{10}$ Biofilm Count, the logged mean $\left(\log _{10}\right)$ biofilm count $\left(\log _{10} \mathrm{CFU} / \mathrm{peg}\right)$ of five replicates at each antimicrobial concentration and time; and Standard Deviation, the standard deviation of five replicates at each antimicrobial concentration and time.

\section{Column 1: Antimicrobial \\ Column 2: Time (h) \\ Column 3: $\log _{10}$ Biofilm Count $\left(\log _{10} \mathrm{CFU}\right)$ \\ Column 4: Standard Deviation}

Dataset Item 8 (Table). Logged mean $\left(\log _{10}\right)$ biofilm count ( $\log _{10} \mathrm{CFU} / \mathrm{peg}$ ) of five positive control replicates for biofilm S. aureus (ATCC 29213) at each time point tabulated at the same time as each tested antimicrobial.

Column 1: Time (h)

Column 2: Vancomycin ( $\left.\log _{10} \mathrm{CFU}\right)$

Column 3: Rifampicin ( $\left.\log _{10} \mathrm{CFU}\right)$

Column 4: Gentamicin ( $\left.\log _{10} \mathrm{CFU}\right)$

Column 5: Ciprofloxacin ( $\left.\log _{10} \mathrm{CFU}\right)$

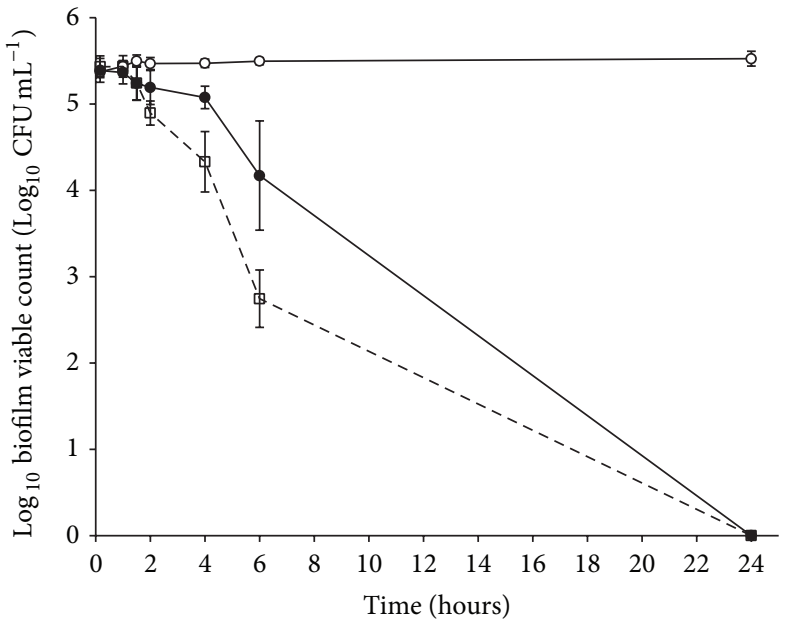

FIGURE 7: $\log _{10}$ graph showing biofilm eradication kinetics and $\log _{10}$ biofilm viable counts ( $\log _{10} \mathrm{CFU} / \mathrm{peg}$ ) of P. aeruginosa (PAO1) (positive control: open circle, full line) over a period of 24 hours of exposure to MBEC value ( $\mathrm{mg} \mathrm{L}^{-1}$ ) of active standard antimicrobials (gentamicin $125 \mathrm{mg} \mathrm{L}^{-1}$ : open square, dotted line; ciprofloxacin $3.91 \mathrm{mg} \mathrm{L}^{-1}$ : full circle, full line) based on five replicates. Vancomycin, trimethoprim, and rifampicin had MBEC values greater than $1000 \mathrm{mg} \mathrm{L}^{-1}$ against $P$. aeruginosa (PAO1) and therefore were not tested for biofilm eradication kinetics.

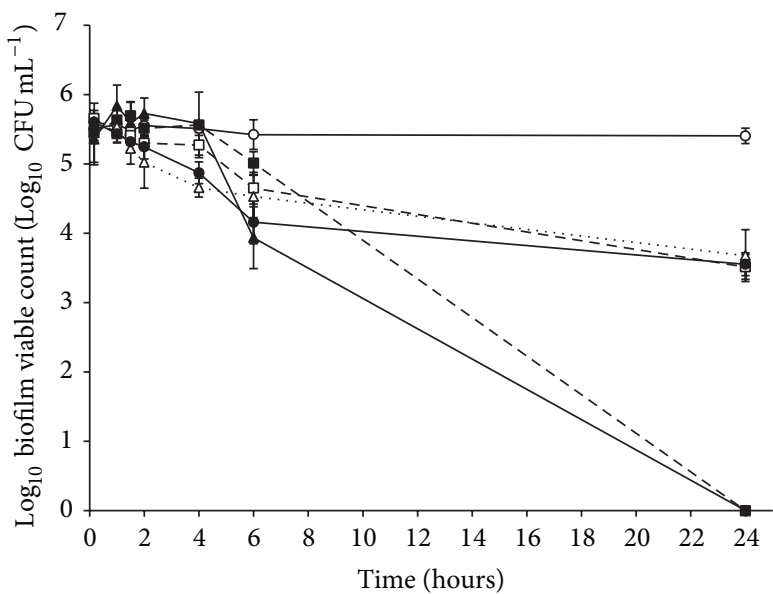

FIGURE 8: $\log _{10}$ graph showing kill kinetics and $\log _{10}$ planktonic viable counts ( $\log _{10} \mathrm{CFU} \mathrm{mL}{ }^{-1}$ ) of E. coli (NCTC 8196) (positive control: open circle, full line) over a period of 24 hours of exposure to four times MIC value $\left(\mathrm{mg} \mathrm{L}^{-1}\right)$ of active standard antimicrobials (vancomycin $1000 \mathrm{mg} \mathrm{L}^{-1}$ : filled square, dotted line; rifampicin $62.5 \mathrm{mg} \mathrm{L}^{-1}$ : filled triangle, full line; gentamicin $10 \mathrm{mg} \mathrm{L}^{-1}$ : open square, dotted line; trimethoprim $1 \mathrm{mg} \mathrm{L}^{-1}$ : open triangle, dotted line; ciprofloxacin $1 \mathrm{mg} \mathrm{L}^{-1}$ : full circle, full line) based on five replicates.

\section{Column 6: $\log _{10}$ Biofilm Count $\left(\log _{10} \mathrm{CFU}\right)$ Column 7: Standard Deviation}

Dataset Item 9 (Table). Rate of kill data (mean) and logged mean $\left(\log _{10}\right)$ for planktonic MRSA (ATCC 43300). In the 


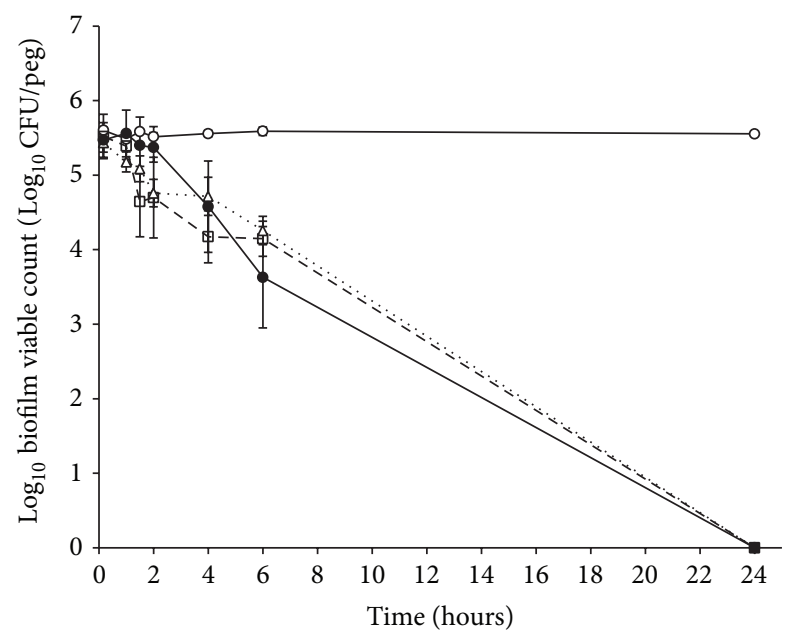

FIGURE 9: $\log _{10}$ graph showing biofilm eradication kinetics and $\log _{10}$ biofilm viable counts ( $\log _{10}$ CFU/peg) of E. coli (NCTC 8196) (positive control: open circles, full line) over a period of 24 hours of exposure to $\mathrm{MBEC}$ value $\left(\mathrm{mg} \mathrm{L}^{-1}\right)$ of active standard antimicrobials (gentamicin $15.63 \mathrm{mg} \mathrm{L}^{-1}$ : open square, dotted line; trimethoprim $62.5 \mathrm{mg} \mathrm{L}^{-1}$ : open triangle, dotted line; ciprofloxacin $7.81 \mathrm{mg} \mathrm{L}^{-1}$ : full circle, full line) based on five replicates. Vancomycin and rifampicin had MBEC values greater than $1000 \mathrm{mg} \mathrm{L}^{-1}$ against of $E$. coli (NCTC 8196) and therefore were not tested for biofilm eradication kinetics.

table, the column Antimicrobial presents the named/relevant antimicrobial and concentration $\left(\mathrm{mg} \mathrm{L}^{-1}\right)$ where colony count was performed; Time, the exposure time (hours); $\log _{10}$ Planktonic Count, the logged mean $\left(\log _{10}\right)$ planktonic count $\left(\log _{10} \mathrm{CFU} \mathrm{mL} \mathrm{L}^{-1}\right)$ of five replicates at each antimicrobial concentration and time; and Standard Deviation, the standard deviation of five replicates at each antimicrobial concentration and time.

Column 1: Antimicrobial

Column 2: Time (h)

Column 3: $\log _{10}$ Planktonic Count

$$
\left(\log _{10} \text { CFU mL }{ }^{-1}\right)
$$

Column 4: Standard Deviation

Dataset Item 10 (Table). Logged mean $\left(\log _{10}\right)$ planktonic count $\left(\log _{10} \mathrm{CFU} \mathrm{mL} \mathrm{m}^{-1}\right)$ of five positive control replicates for planktonic MRSA (ATCC 43300) at each time point tabulated at the same time as each tested antimicrobial.

$$
\begin{aligned}
& \text { Column 1: Time (h) } \\
& \text { Column 2: Vancomycin }\left(\log _{10} \mathrm{CFU} \mathrm{mL} \mathrm{m}^{-1}\right) \\
& \text { Column 3: Rifampicin }\left(\log _{10} \mathrm{CFU} \mathrm{mL}{ }^{-1}\right) \\
& \text { Column 4: Gentamicin }\left(\log _{10} \mathrm{CFU} \mathrm{mL} \mathrm{m}^{-1}\right) \\
& \text { Column 5: Trimethoprim }\left(\log _{10} \mathrm{CFU} \mathrm{mL} L^{-1}\right) \\
& \text { Column 6: Ciprofloxacin }\left(\log _{10} \mathrm{CFU} \mathrm{mL} \mathrm{L}^{-1}\right) \\
& \text { Column 7: } \log _{10} \text { Planktonic Count } \\
& \left(\log _{10} \text { CFU mL }{ }^{-1}\right)
\end{aligned}
$$

Dataset Item 11 (Table). Rate of kill data (mean) and logged mean $\left(\log _{10}\right)$ for planktonic P. aeruginosa (PAO1). In the table, the column Antimicrobial presents the named/relevant antimicrobial and concentration $\left(\mathrm{mg} \mathrm{L}^{-1}\right)$ where colony count was performed; Time, the exposure time (hours); $\log _{10}$ Planktonic Count, the logged mean $\left(\log _{10}\right)$ planktonic count $\left(\log _{10} \mathrm{CFU} \mathrm{mL} L^{-1}\right)$ of five replicates at each antimicrobial concentration and time; and Standard Deviation, the standard deviation of five replicates at each antimicrobial concentration and time.

$$
\begin{aligned}
\text { Column 1: } & \text { Antimicrobial } \\
\text { Column 2: } & \text { Time (h) } \\
\text { Column 3: } & \log _{10} \text { Planktonic Count } \\
& \left(\log _{10} \mathrm{CFU} \mathrm{mL} \mathrm{mL}^{-1}\right)
\end{aligned}
$$

Column 4: Standard Deviation

Dataset Item 12 (Table). Logged mean $\left(\log _{10}\right)$ planktonic count $\left(\log _{10} \mathrm{CFU} \mathrm{mL} \mathrm{m}^{-1}\right)$ of five positive control replicates for planktonic $P$. aeruginosa (PAO1) at each time point tabulated at the same time as each tested antimicrobial.

Column 1: Time (h)

Column 2: Rifampicin $\left(\log _{10} \mathrm{CFU} \mathrm{mL} \mathrm{m}^{-1}\right)$

Column 3: Gentamicin $\left(\log _{10} \mathrm{CFU} \mathrm{mL} \mathrm{m}^{-1}\right)$

Column 4: Ciprofloxacin $\left(\log _{10} \mathrm{CFU} \mathrm{mL} \mathrm{L}^{-1}\right)$

Column 5: $\log _{10}$ Planktonic Count

$$
\left(\log _{10} \mathrm{CFU} \mathrm{mL}{ }^{-1}\right)
$$

Column 6: Standard Deviation

Dataset Item 13 (Table). Rate of kill data (mean) and logged mean $\left(\log _{10}\right)$ for biofilm P. aeruginosa (PAO1). Vancomycin, trimethoprim, and rifampicin had MBEC values greater than $1000 \mathrm{mg} \mathrm{L}^{-1}$ against $P$. aeruginosa (PAOl) and therefore were not tested for biofilm eradication kinetics. In the table, the column Antimicrobial presents the named/relevant antimicrobial and concentration $\left(\mathrm{mg} \mathrm{L}^{-1}\right)$ where colony count was performed; Time, the exposure time (hours); $\log _{10}$ Biofilm Count, the logged mean $\left(\log _{10}\right)$ biofilm count $\left(\log _{10}\right.$ $\mathrm{CFU} / \mathrm{peg}$ ) of five replicates at each antimicrobial concentration and time; and Standard Deviation, the standard deviation of five replicates at each antimicrobial concentration and time.

Column 1: Antimicrobial

Column 2: Time (h)

Column 3: $\log _{10}$ Biofilm Count ( $\left.\log _{10} \mathrm{CFU}\right)$

Column 4: Standard Deviation

Dataset Item 14 (Table). Logged mean $\left(\log _{10}\right)$ biofilm count ( $\log _{10} \mathrm{CFU} / \mathrm{peg}$ ) of five positive control replicates for biofilm $P$. aeruginosa (PAO1) at each time point tabulated at the same time as each tested antimicrobial.

Column 1: Time (h)

Column 2: Gentamicin ( $\left.\log _{10} \mathrm{CFU}\right)$ 
Column 3: Ciprofloxacin $\left(\log _{10} \mathrm{CFU}\right)$

Column 4: $\log _{10}$ Biofilm Count $\left(\log _{10} \mathrm{CFU}\right)$

Column 5: Standard Deviation

Dataset Item 15 (Table). Rate of kill data (mean) and logged mean $\left(\log _{10}\right)$ for planktonic E. coli (NCTC 8196). In the table, the column Antimicrobial presents the named/relevant antimicrobial and concentration $\left(\mathrm{mgL}^{-1}\right)$ where colony count was performed; Time, the exposure time (hours); $\log _{10}$ Planktonic Count, the logged mean $\left(\log _{10}\right)$ planktonic count $\left(\log _{10} \mathrm{CFU} \mathrm{mL} \mathrm{m}^{-1}\right)$ of five replicates at each antimicrobial concentration and time; and Standard Deviation, the standard deviation of five replicates at each antimicrobial concentration and time.

Column 1: Antimicrobial

Column 2: Time (h)

Column 3: $\log _{10}$ Planktonic Count

$\left(\log _{10}\right.$ CFU mL $\left.{ }^{-1}\right)$

Column 4: Standard Deviation

Dataset Item 16 (Table). Logged mean $\left(\log _{10}\right)$ planktonic count $\left(\log _{10} \mathrm{CFU} \mathrm{mL} \mathrm{m}^{-1}\right.$ ) of five positive control replicates for planktonic E. coli (NCTC 8196) at each time point tabulated at the same time as each tested antimicrobial.

$$
\begin{aligned}
& \text { Column 1: Time (h) } \\
& \text { Column 2: Vancomycin }\left(\log _{10} \mathrm{CFU} \mathrm{mL}\right. \\
& \text { Column 3: Rifampicin }\left(\log _{10} \mathrm{CFU} \mathrm{mL}\right. \\
& \text { Column 4: Gentamicin }\left(\log _{10} \mathrm{CFU} \mathrm{mL}\right. \\
& \text { Column 5: Trimethoprim }\left(\log _{10} \mathrm{CFU} \mathrm{mL}\right. \\
& \text { Column 6: Ciprofloxacin }\left(\log _{10} \mathrm{CFU} \mathrm{mL}\right. \\
& \text { Column 7: } \log _{10} \text { Planktonic Count } \\
& \\
& \quad\left(\log _{10} \mathrm{CFU} \mathrm{mL}^{-1}\right)
\end{aligned}
$$

Column 8: Standard Deviation

Dataset Item 17 (Table). Rate of kill data (mean) and logged mean $\left(\log _{10}\right)$ for biofilm E. coli (NCTC 8196). Vancomycin and rifampicin had MBEC values greater than $1000 \mathrm{mg} \mathrm{L}^{-1}$ against of E. coli (NCTC 8196) and therefore were not tested for biofilm eradication kinetics. In the table, the column Antimicrobial presents the named/relevant antimicrobial and concentration $\left(\mathrm{mg} \mathrm{L}^{-1}\right)$ where colony count was performed; Time, the exposure time (hours); $\log _{10}$ Biofilm Count, the logged mean $\left(\log _{10}\right)$ biofilm count $\left(\log _{10} \mathrm{CFU} / \mathrm{peg}\right)$ of five replicates at each antimicrobial concentration and time; and Standard Deviation, the standard deviation of five replicates at each antimicrobial concentration and time.

Column 1: Antimicrobial

Column 2: Time (h)

Column 3: $\log _{10}$ Biofilm Count $\left(\log _{10} \mathrm{CFU}\right)$

Column 4: Standard Deviation
Dataset Item 18 (Table). Logged mean $\left(\log _{10}\right)$ biofilm count ( $\log _{10} \mathrm{CFU} / \mathrm{peg}$ ) of five positive control replicates for biofilm E. coli (NCTC 8196) at each time point tabulated at the same time as each tested antimicrobial.

\author{
Column 1: Time (h) \\ Column 2: Gentamicin ( $\left.\log _{10} \mathrm{CFU}\right)$ \\ Column 3: Trimethoprim ( $\left.\log _{10} \mathrm{CFU}\right)$ \\ Column 4: Ciprofloxacin $\left(\log _{10} \mathrm{CFU}\right)$ \\ Column 5: $\log _{10}$ Biofilm Count $\left(\log _{10} \mathrm{CFU}\right)$ \\ Column 6: Standard Deviation
}

\section{Concluding Remarks}

The use of standard antimicrobials in biomaterial-associated infection is to either salvage the medical device or prevent infection by incorporation of the antimicrobial into the device $[25,34]$. As the results obtained have shown there are differences in both the spectrum of activity of the antimicrobials and also in their relative activity against planktonic and biofilm forms of these numerous device related pathogens. The formation of biofilms by microorganisms leads to an almost universal ten- to one-thousand-fold increase in the concentration of antimicrobial required to eradicate established infection [35]. This paper is significant in providing in vitro data on standardly used antibiotic regimens to inform the initial clinical treatment choice for medical device related infections. None of the antimicrobials tested were fully microbicidal against all forms of Grampositive and Gram-negative microorganisms researched at the concentrations tested. Thus, as is the case clinically, it is often required to use combinations of antimicrobials both to provide better antimicrobial coverage in the treatment of infection and to reduce the incidence of resistance developing to a particular antimicrobial [36]. Rifampicin had the best activity against Gram-positive microorganisms with gentamicin possessing the greatest spectrum of activity overall. The Gram-negative microorganisms were most susceptible to ciprofloxacin. Despite its mainly intracellular action rifampicin showed excellent kill kinetics of both planktonic $\left(1 \mathrm{mg} \mathrm{L}^{-1}\right)$ and biofilm $\left(15.63 \mathrm{mg} \mathrm{L}^{-1}\right)$ forms of $S$. aureus (ATCC 29213) within 1.5 and 6 hours, respectively. However in the majority of cases where an MBEC value was obtained, a 24-hour challenge with the antimicrobial was required to completely eradicate the biofilm. This delay in kill is crucial in promoting the formation of resistant microorganisms, particularly of the sessile biofilm form and persister cells. The incidence of resistance to standard antimicrobial regimens and the need for novel antimicrobial compounds with multiple modes of action are increasing [37]. Therefore obtaining the MIC, MBC, and MBEC values and establishing the kill kinetics of these standard antimicrobials against experimental biofilm forming isolates allow comparisons to be made with values obtained for novel compounds, such as antimicrobial peptides [38], with their relative effectiveness judged accordingly. There is also the potential that these novel compounds may act synergistically with standard antimicrobials to lower both the development 
of microbial resistance and the therapeutic doses required to resolve or prevent infection.

\section{Dataset Availability}

The dataset associated with this Dataset Paper is dedicated to the public domain using the CC0 waiver and is available at http://dx.doi.org/10.1155/2014/250694/dataset.

\section{Conflict of Interests}

The authors declare that there is no conflict of interests regarding the publication of this paper.

\section{References}

[1] J. P. Guggenbichler, O. Assadian, M. Boeswald, and A. Kramer, "Incidence and clinical implication of nosocomial infections associated with implantable biomaterials-catheters, ventilatorassociated pneumonia, urinary tract infections," GMS Krankenhhyg Interdiszip, vol. 6, no. 1, article 18, 2011.

[2] K. Lewis, "Multidrug tolerance of biofilms and persister cells," Current Topics in Microbiology and Immunology, vol. 322, pp. 107-131, 2008.

[3] K. R. Allison, M. P. Brynildsen, and J. J. Collins, "Heterogeneous bacterial persisters and engineering approaches to eliminate them," Current Opinion in Microbiology, vol. 14, no. 5, pp. 593598, 2011.

[4] M. E. Hulscher, R. P. Grol, and J. W. van der Meer, "Antibiotic prescribing in hospitals: a social and behavioural scientific approach," The Lancet Infectious Diseases, vol. 10, no. 3, pp. 167$175,2010$.

[5] L. A. Mermel, M. Allon, E. Bouza et al., "Clinical practice guidelines for the diagnosis and management of intravascular catheter-related infection: 2009 update by the Infectious Diseases Society of America," Clinical Infectious Diseases, vol. 49, no. 1, pp. 1-45, 2009.

[6] M. B. Bestul and H. L. VandenBussche, "Antibiotic lock technique: review of the literature," Pharmacotherapy, vol. 25, no. 2, pp. 211-227, 2005.

[7] J. A. Capdevila, A. Segarra, A. M. Planes et al., "Successful treatment of haemodialysis catheter-related sepsis without catheter removal," Nephrology Dialysis Transplantation, vol. 8, no. 3, pp. 231-234, 1993.

[8] J.-L. Benoit, G. Carandang, M. Sitrin, and P. M. Arnow, "Intraluminal antibiotic treatment of central venous catheter infections in patients receiving parenteral nutrition at home," Clinical Infectious Diseases, vol. 21, no. 5, pp. 1286-1288, 1995.

[9] H. Bagnall-Reeb, "Evidence for the use of the antibiotic lock technique," Journal of Infusion Nursing, vol. 27, no. 2, pp. 118122,2004

[10] C. Rotstein, L. Brock, and R. S. Roberts, “The incidence of first Hickman catheter-related infection and predictors of catheter removal in cancer patients," Infection Control and Hospital Epidemiology, vol. 16, no. 8, pp. 451-458, 1995.

[11] P. M. Arnow, E. M. Quimosing, and M. Beach, "Consequences of intravascular catheter sepsis," Clinical Infectious Diseases, vol. 16, no. 6, pp. 778-784, 1993.

[12] J. Rodriguez-Bano, "Selection of empiric therapy in patients with catheter-related infections," Clinical Microbiology and Infection, vol. 8, no. 5, pp. 275-281, 2002.
[13] W. Graninger, O. Assadian, H. Lagler, and M. Ramharter, "The role of glycopeptides in the treatment of intravascular catheterrelated infections," Clinical Microbiology and Infection, vol. 8, no. 5, pp. 310-315, 2002.

[14] M. P. Ruiz-Valverde, J. R. Barberà, A. Segarra, J. A. Capdevila, A. Evangelista, and L. Piera, "Successful treatment of catheterrelated sepsis and extraluminal catheter thrombosis with vancomycin and fraxiparin without catheter removal," Nephron, vol. 75, no. 3, pp. 354-355, 1997.

[15] J. M. Boyce, L. A. Mermel, M. J. Zervos et al., "Controlling vancomycin-resistant enterococci," Infection Control and Hospital Epidemiology, vol. 16, no. 11, pp. 634-637, 1995.

[16] L. A. Mermel, B. M. Farr, R. J. Sherertz et al., "Guidelines for the management of intravascular catheter-related infections," Clinical Infectious Diseases, vol. 32, no. 9, pp. 1249-1272, 2001.

[17] G. Peters and K. Becker, "Epidemiology, control and treatment of methicillin-resistant Staphylococcus aureus," Drugs, vol. 52, supplement 2, pp. 50-54, 1996.

[18] H. N. Bentur, A. M. Dalzell, and F. A. I. Riordan, "Central venous catheter infection with Bacillus pumilus in an immunocompetent child: a case report," Annals of Clinical Microbiology and Antimicrobials, vol. 6, article 12, 2007.

[19] J. H. Crabtree and N. A. Garcia, "Corynebacterium striatum peritoneal dialysis catheter exit site infection," Clinical Nephrology, vol. 60, no. 4, pp. 270-274, 2003.

[20] D. S. Swanson, "Central venous catheter-related infections due to nontuberculous Mycobacterium species," Pediatric Infectious Disease Journal, vol. 17, no. 12, pp. 1163-1164, 1998.

[21] D. R. P. Guay, "Nontuberculous mycobacterial infections," Annals of Pharmacotherapy, vol. 30, no. 7-8, pp. 819-830, 1996.

[22] M. V. Gill, H. Ly, M. Mueenuddin, P. E. Schoch, and B. A. Cunha, "Intravenous line infection due to Ochrobactrum anthropi (CDC group Vd) in a normal host," Heart \& Lung, vol. 26, no. 4, pp. 335-336, 1997.

[23] M. J. Ashby, J. E. Neale, S. J. Knott, and I. A. Critchley, "Effect of antibiotics on non-growing planktonic cells and biofilms of Escherichia coli," Journal of Antimicrobial Chemotherapy, vol. 33, no. 3, pp. 443-452, 1994.

[24] H. Ishida, Y. Ishida, Y. Kurosaka, T. Otani, K. Sato, and H. Kobayashi, "In vitro and in vivo activities of levofloxacin against biofilm-producing Pseudomonas aeruginosa," Antimicrobial Agents and Chemotherapy, vol. 42, no. 7, pp. 1641-1645, 1998.

[25] E. Bouza, A. Burillo, and P. Muñoz, "Catheter-related infections: diagnosis and intravascular treatment," Clinical Microbiology and Infection, vol. 8, no. 5, pp. 265-274, 2002.

[26] S. Stepanović, D. Vuković, I. Dakić, B. Savić, and M. ŠvabićVlahović, "A modified microtiter-plate test for quantification of staphylococcal biofilm formation," Journal of Microbiological Methods, vol. 40, no. 2, pp. 175-179, 2000.

[27] G. Laverty, M. McLaughlin, C. Shaw, S. P. Gorman, and B. F. Gilmore, "Antimicrobial activity of short, synthetic cationic lipopeptides," Chemical Biology \& Drug Design, vol. 75, no. 6, pp. 563-569, 2010.

[28] H. Ceri, M. E. Olson, C. Stremick, R. R. Read, D. Morck, and A. Buret, "The calgary biofilm device: new technology for rapid determination of antibiotic susceptibilities of bacterial biofilms," Journal of Clinical Microbiology, vol. 37, no. 6, pp. 1771$1776,1999$.

[29] C. W. Stratton, C. Liu, H. B. Ratner, and L. S. Weeks, "Bactericidal activity of deptomycin (LY146032) compared with those of ciprofloxacin, vancomycin, and ampicillin against enterococci 
as determined by kill-kinetic studies," Antimicrobial Agents and Chemotherapy, vol. 31, no. 7, pp. 1014-1016, 1987.

[30] C. W. Stratton, C. Liu, and L. S. Weeks, "Activity of LY146032 compared with that of methicillin, cefazolin, cefamandole, cefuroxime, ciprofloxacin, and vancomycin against staphylococci as determined by kill-kinetic studies," Antimicrobial Agents and Chemotherapy, vol. 31, no. 8, pp. 1210-1215, 1987.

[31] G. A. Pankuch, M. R. Jacobs, and P. C. Appelbaum, "Study of comparative antipneumococcal activities of penicillin $G$, RP 59500, erythromycin, sparfloxacin, ciprofloxacin, and vancomycin by using time-kill methodology," Antimicrobial Agents and Chemotherapy, vol. 38, no. 9, pp. 2065-2072, 1994.

[32] K. Smith, A. Perez, G. Ramage, C. G. Gemmell, and S. Lang, "Comparison of biofilm-associated cell survival following in vitro exposure of meticillin-resistant Staphylococcus aureus biofilms to the antibiotics clindamycin, daptomycin, linezolid, tigecycline and vancomycin," International Journal of Antimicrobial Agents, vol. 33, no. 4, pp. 374-378, 2009.

[33] A. A. Miles, S. S. Misra, and J. O. Irwin, "The estimation of the bactericidal power of the blood," Journal of Hygiene, vol. 38, no. 6, pp. 732-749, 1938.

[34] P. Wu and D. W. Grainger, "Drug/device combinations for local drug therapies and infection prophylaxis," Biomaterials, vol. 27, no. 11, pp. 2450-2467, 2006.

[35] N. Balaban, A. Giacometti, O. Cirioni et al., "Use of the quorumsensing inhibitor RNAIII-inhibiting peptide to prevent biofilm formation in vivo by drug-resistant Staphylococcus epidermidis," Journal of Infectious Diseases, vol. 187, no. 4, pp. 625-630, 2003.

[36] N. P. O'Grady, M. Alexander, E. P. Dellinger et al., "Guidelines for the prevention of intravascular catheter-related infections. Centers for Disease Control and Prevention," MMWR. Recommendations and Reports, vol. 51, no. 10, pp. 1-29, 2002.

[37] C. Perry and C. Hall, "Antibiotic resistance: how it arises, the current position and strategies for the future," Nursing Times, vol. 105, no. 36, pp. 20-23, 2009.

[38] G. Laverty, S. P. Gorman, and B. F. Gilmore, "The potential of antimicrobial peptides as biocides," International Journal of Molecular Sciences, vol. 12, no. 10, pp. 6566-6596, 2011. 

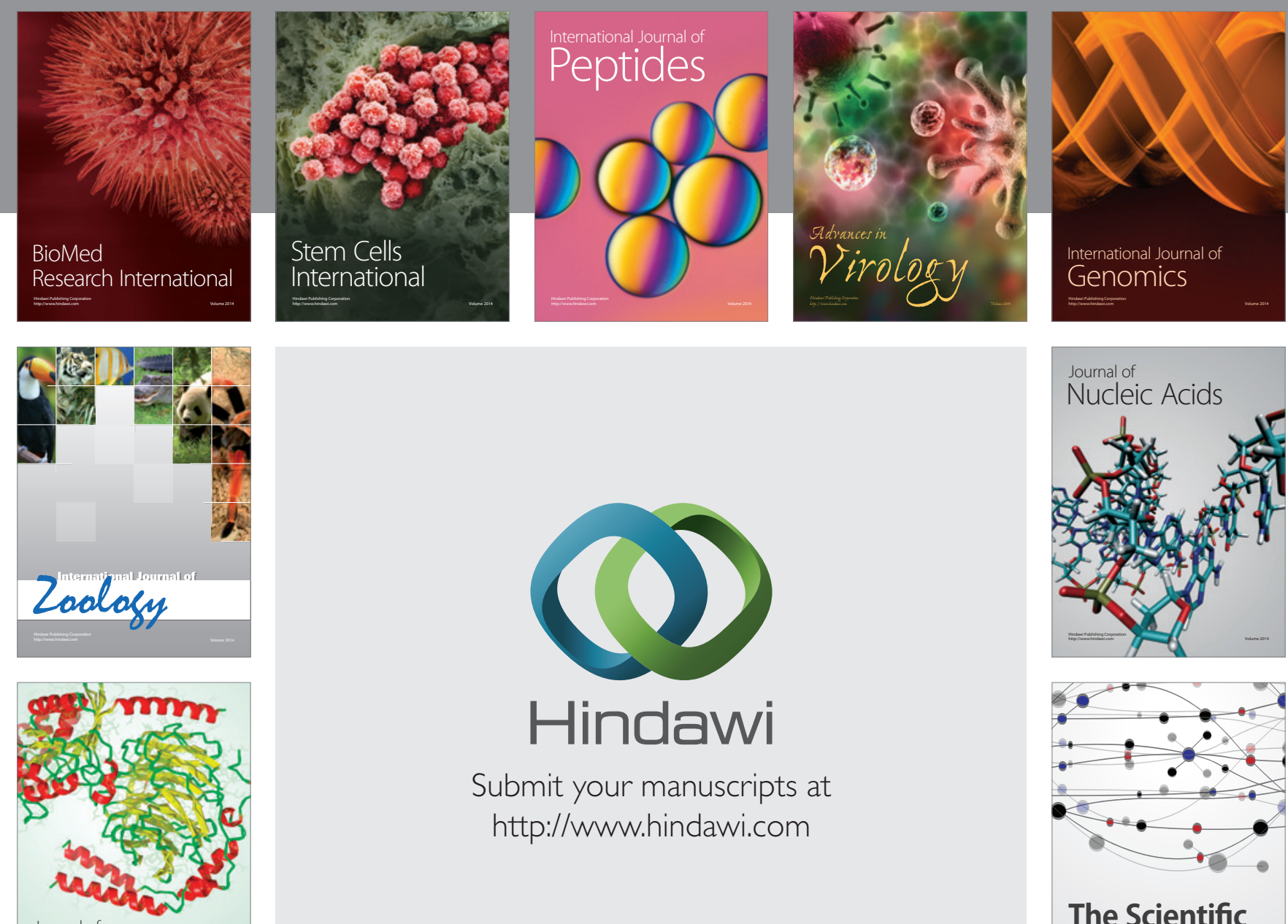

Submit your manuscripts at

http://www.hindawi.com

Journal of
Signal Transduction
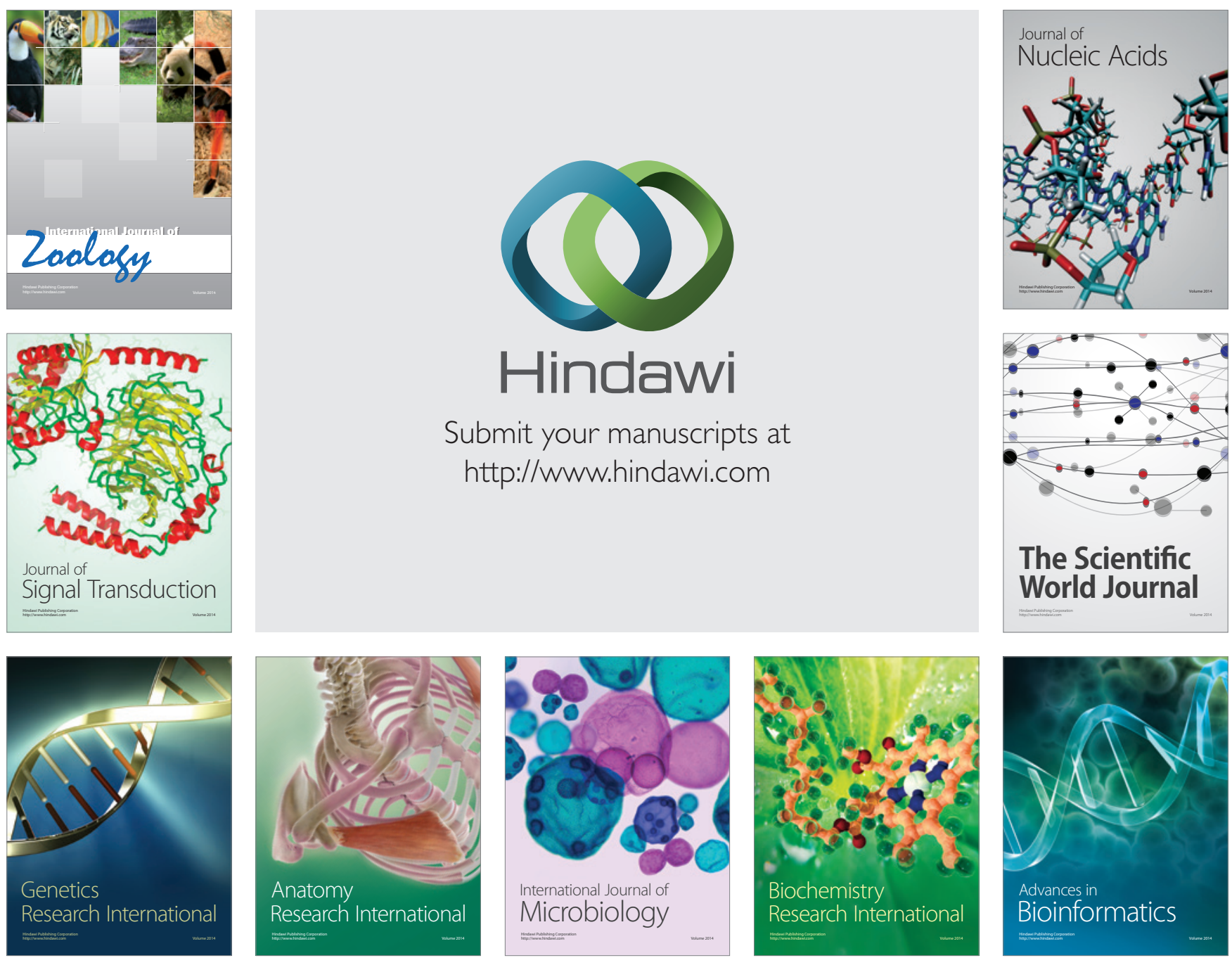

The Scientific World Journal
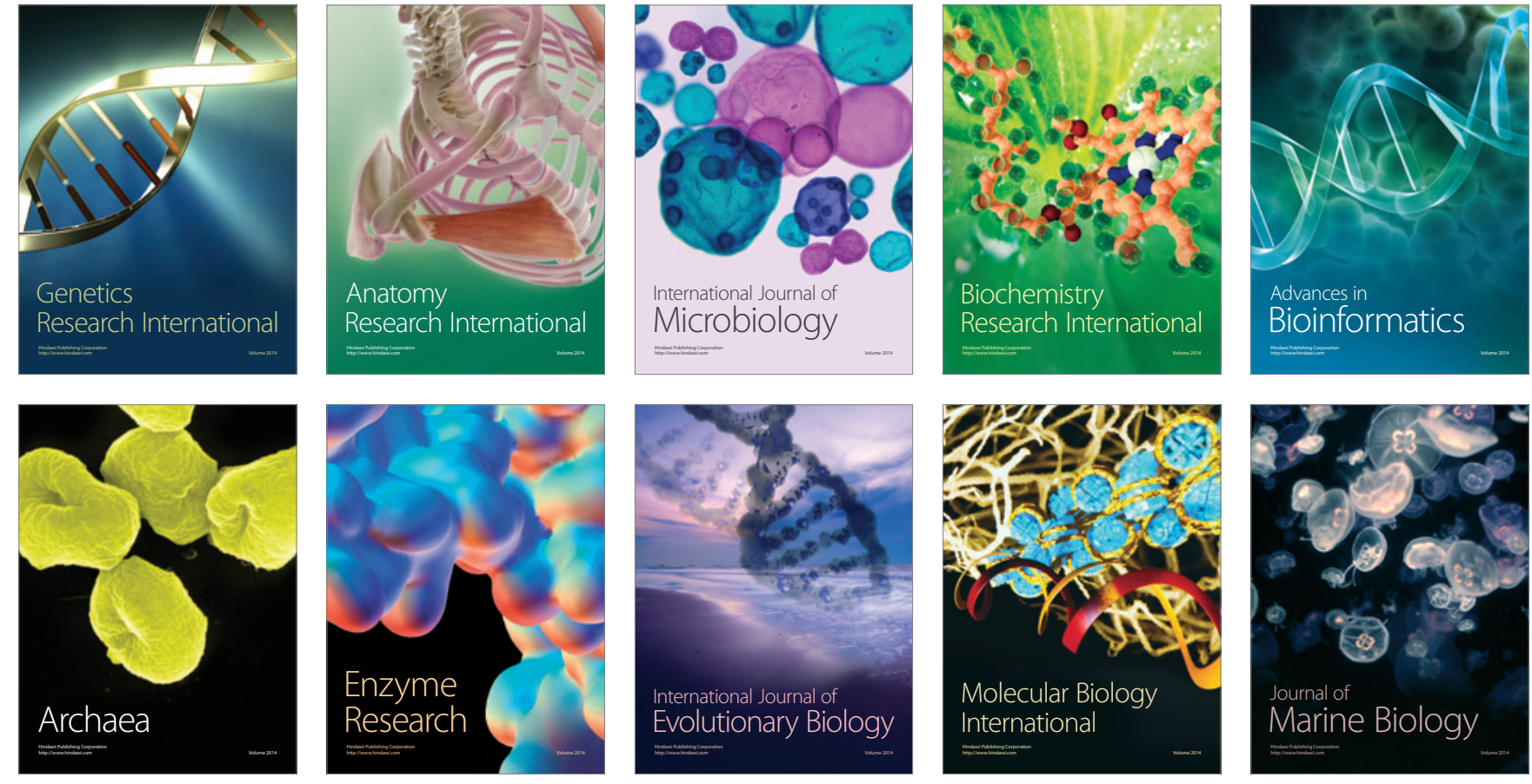